\title{
Human Lifeways
}

\section{Barry Taylor, Chantal Conneller, Nicky Milner, Ben Elliott, Aimée Little, Becky Knight and Michael Bamforth}

\section{Introduction}

Just like Clark, our motivations in excavating Star Carr were to understand the lives of the people who lived at the site and, through them, to learn more about the people who inhabited this part of North-west Europe in the centuries following the end of the Younger Dryas cold phase (the Loch Lomond stadial in the British sequence; see Chapter 4). The material remains recovered from the site provide a wealth of information on economic and technical practices. However, these remains are also the products of relationships with other people, animals, plants and places. They are the results of decisions and actions not simply dictated by economic and functional considerations but by broader understandings of the world that people inhabited.

\section{The treatment of animals}

The inhabitants of Star Carr shared their landscape with a diverse population of animals, many of which were probably present within and around the lake itself. Though they would have avoided areas of human habitation, both elk and wild boar favour mosaic habitats of woodland and wetland of the sorts that would be found along the lake shore, whilst red and roe deer and (probably) aurochs may have inhabited the surrounding woodlands, coming to the lake to drink or to browse on the thickets of willow and aspen that were growing at the water's edge (Overton and Taylor forthcoming). The woodlands would also have been the habitats of the smaller mammals, such as pine marten, wild cat, badger, fox and hare. From the finds of beaver worked wood, beavers were visiting Star Carr and other areas around Lake Flixton to feed, and were probably living within the lake itself, along with pike and perch. Waterfowl were also visitors to the area, inhabiting the reed beds or the more open areas of water.

Our knowledge of these animals comes from the faunal assemblage recorded from the site during both the current project and the previous excavations. There has been a tendency to interpret this material in terms of its economic value and discuss it within the context of subsistence strategies. However, these are relatively narrow aspects of a much wider and complex relationship between Mesolithic people and the other animal species that inhabited this landscape. This relationship would have been articulated through the different ways

How to cite this book chapter:

Taylor, B., Conneller, C., Milner, N., Elliott, B., Little, A., Knight, B. and Bamforth, M. 2018. Human Lifeways. In: Milner, N., Conneller, C. and Taylor, B. (eds.) Star Carr Volume 1: A Persistent Place in a Changing World, pp. 245-272. York: White Rose University Press. DOI: https://doi.org/10.22599/book1.j. Licence: CC BY-NC 4.0 
in which animals were hunted, the traces they left in the landscape, and the remains of their bodies that were butchered and used as food, worked into objects, or deposited in different ways across the site. Yet this relationship extended beyond hunting and encounters which resulted in the death of animals. The inhabitants of Star Carr shared their landscape with these different species: there is no evidence to suggest any of these species became locally extinct during the occupation of Star Carr. As such, this relationship would also have been shaped by chance encounters within the landscape; animals seen, heard or smelt, but not hunted; tracks seen but not followed. These relationships can be explored through the analysis and interpretation of the remains of the animals, their treatment, and they ways in which they were deposited on site, as well as an appreciation of the behaviour of modern-day populations of these species.

\section{Hunting technology and strategy}

We can start by considering the ways in which the animals were hunted. We know from impact wounds found on the bones of animals at Star Carr and other European Mesolithic sites, that the larger animals, such as deer, elk, aurochs and wild boar, were probably killed by groups of people, armed with projectiles such as arrows, javelins, thrusting spears or darts, tipped with flint, bone or antler.

At Star Carr, hunting wounds were present on the scapulae of two elk and a red deer (Noe-Nygaard 1975; Legge and Rowley-Conwy 1988), and similar injuries have been recorded on the ribs, scapula and vertebrae of a range of medium and large mammals from Mesolithic contexts in Denmark (Noe-Nygaard 1974; Leduc 2014a). These include injuries sustained by weapons propelled towards the front of the animal, such as an arrow tip embedded in the humerus of a juvenile red deer in the Åmose peat bog and a healed fracture on the scapula of an adult deer from Jordløse, and from above, as well as from the sides and rear (Noe-Nygaard 1974; Leduc 2014a). In several cases there is evidence that animals were attacked by multiple assailants, notably the aurochs from Vig, which had been struck by an arrow and a spear (Noe-Nygaard 1973), and the aurochs from Prejlerup, which had 24 microliths recorded from different areas of the body (Fischer 1989), though these may represent cases of 'overkill' associated with unusual depositional contexts (Strassburg 2000).

The weaponry used to hunt these animals is well represented in the assemblage from Star Carr. Several of the flint microliths and blades have impact damage and use traces indicative of their employment as the tips and barbs of projectiles, whilst the barbed points (several of which also have impact damage on their tips and use wear from being hafted) would be suitable as the points of arrows, javelins or thrusting spears (Figure 10.1). Whilst we lack the shafts of the projectiles, there is considerable evidence for the manufacture of dowels which would have been suitable for either arrows or spears.

As well as weapons, other forms of technology may also have been utilised. Though we lack the archaeological evidence, it is possible that hunters used decoys or callers to mimic sounds of animals such as elk and red deer and attract them to points where they could be ambushed. Similarly, hunters may have worn disguises allowing them to approach their prey, a function that has sometimes been attributed to the red deer antler frontlets recovered from Star Carr (Clark 1954).

The methods employed to hunt and then kill animals would have been based upon the hunter's previous encounters with them, encounters that were either with the animals themselves or the traces they left in the landscape. This could include areas of more intensive browsing visible in the growth patterns of young saplings, marks left by red deer stags as they rubbed their antlers on trees to demarcate their territories, or broken branches and paths visible in the understorey as animals moved through the woodland. Through these observations the hunters would become aware of the different habitats and behaviours of particular species of animals, either in particular situations or at certain times of the year and how these differ with age, and then use this knowledge to predict areas in the landscape where the animals might be found and to devise strategies to engage them. This understanding of animal behaviour is likely to have been passed down between generations but would also have been adapted to suit the changing nature of the local environment.

Figure 10.1 (page 247): A replica barbed point showing traces of animal blood after being hafted and shot from a bow into an animal carcass (Copyright Aimée Little, CC BY-NC 4.0). 
Depending upon their motivations, the hunters at Star Carr may have acted speculatively, travelling to areas where they knew a range of animals may be present, or visited specific locations where a particular species might be found. This may have included the extensive areas of wetland that were forming in the large, shallow embayment at the western end of the lake, an area where (to date) we have little evidence for very Early Mesolithic activity. Here, the clear open aspects and easy access to water may have made the area attractive to many of the larger mammals, as well as providing areas of aquatic vegetation on which elk could graze. They may also have sought out the thickets of willow and aspen that were established along parts of the lake shore, where the good lines of sight and easy access to browse may have attracted animals such as elk or red deer (Ripple and Beschta 2004). As more extensive areas of tree cover developed after the first centuries of the Mesolithic, people would have visited areas within the terrestrial woodland where specific animals had established territories.

These journeys to different places in the landscape may have been undertaken on foot, possibly following established trails through woodland or along parts of the lake shore, but they may also have been carried out by boat (Rowley-Conwy 2017). Though we lack evidence for watercraft, it is very likely that boats would have been used to travel around and across the lake, particularly given the presence of Early Mesolithic activity on both of the two islands. The lack of large trees in the very Early Mesolithic landscape make it unlikely that these boats would have been dugout canoes of the kind found on later Mesolithic sites such as Tybrind Vig (Andersen 2013). Instead, people were probably using open craft, made from skins or bark placed over a wooden frame, similar to the currachs of Ireland and the west coast of Scotland, or watercraft used by indigenous groups in North America (e.g. Adney and Chappelle 1964). The possible paddle fragment recorded by Clark $(1954,177)$ may have been used to propel such boats, though given its small size the interpretation of this artefact as a paddle is open to debate (see Chapter 29).

Given the cooperative nature of hunting and the size of the animals they sought, we can assume that the hunters operated as a group, most likely made up of different members of their community. Whilst hunting is often assumed to be an all-male activity in much of the archaeological literature, ethnographic studies have shown that gender restrictions often only relate to the act of killing an animal and that both men and women may participate in the hunt itself. The group would also have included people of different ages and probably

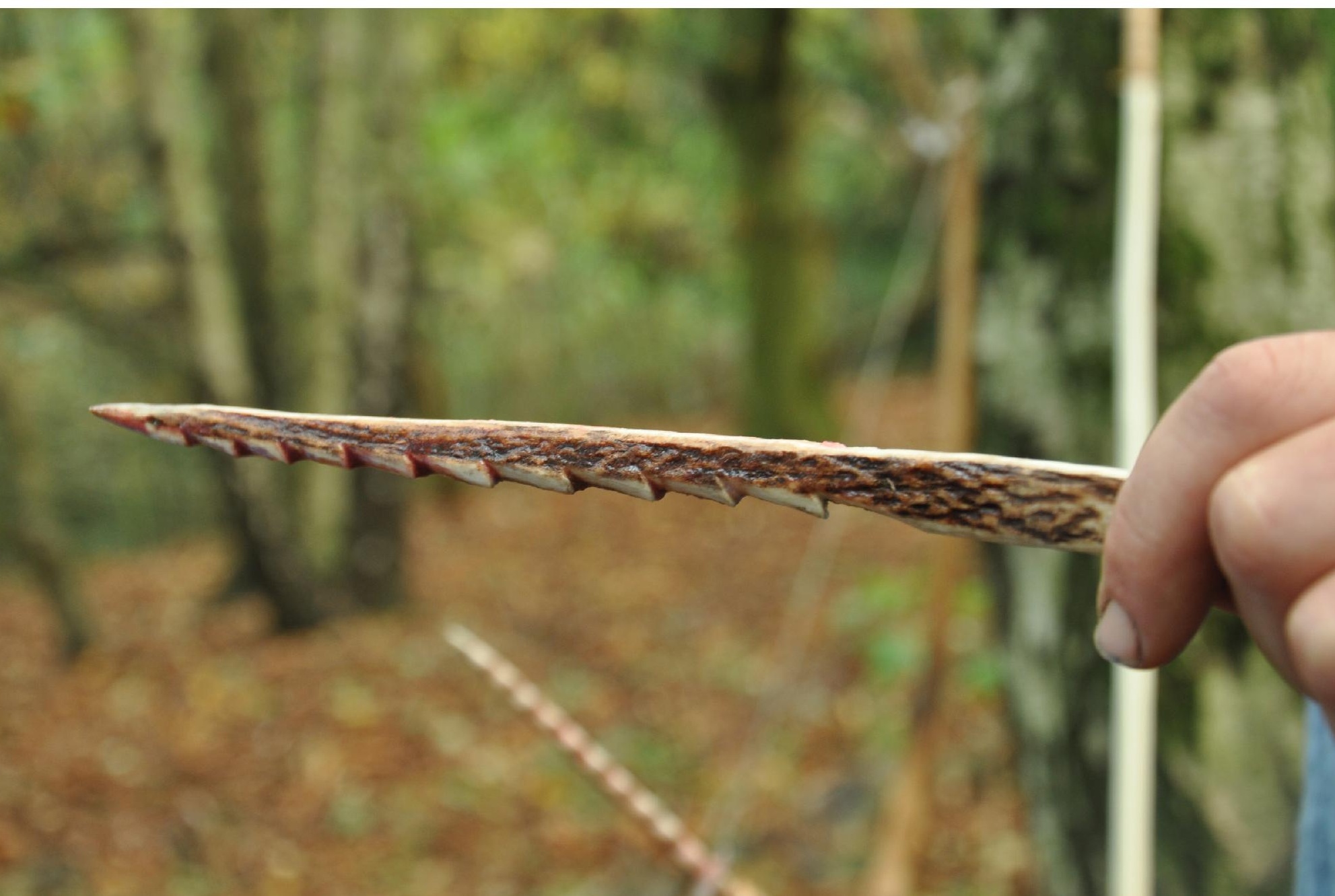


different familial or social relationships. Ethnographies of learning within hunter-gatherer groups describe the role that children can play within hunting activities, often using miniaturised (but not toy) hunting tools to actively participate in the hunting of birds and small game; thus making a significant economic and socially valued contribution, whilst learning the basic skills of hunting (Cattelain 1997). With this in mind, it may be worth considering that the smaller barbed points within the Star Carr assemblage may have served as miniaturised hunting tools for novice hunters (Elliott 2009).

As they travelled the hunters would have used the physical traces left by animals, such as damage on trees, fresh tracks, or dung, to establish their recent presence in the area. Then, specific strategies would be used to locate and then kill the animal depending upon the behaviour of the particular species, its age, and the time of year. Modern Kutchin hunters, for example, take advantage of the elk's tendency to double back on itself in their strategies for stalking the animal by intercepting it along points in its trail (Nelson 1986). Similarly, the recurrent behavioural habit of red deer coming to forest fringes to browse in the twilight of dawn and dusk is noted in a range of contexts and may well have drawn them to the edges of the lake or clearings deeper within the forest at specific times of day. In some cases, animals would have been stalked and killed individually, in others hunters would have flushed groups of animals from cover, picking off individual animals as they dispersed.

From the range of species present in the faunal assemblage from Star Carr it is clear that hunters did not focus exclusively on a single animal species. However, the age-at-death profiles show that they preferentially targeted animals of certain ages. In the case of red deer, hunters seem to have particularly targeted young individuals aged between three and five, just after males have left their mothers permanently (Legge and Rowley-Conwy 1988). Roe deer appear to have been hunted and killed when they were younger, though again this corresponds with the age at which the young males and females are driven away from their mothers. Legge and RowleyConwy (1988) have argued that these patterns reflect a hunting strategy targeting younger, inexperienced animals, who in the case of roe deer may have occupied more exposed, marginal habitats. However, amongst the red deer the vulnerable male yearlings, chased away from their mothers by adult males, are rarely represented in the faunal assemblage, suggesting that the older animals were seen as more appropriate to kill.

Though large-mammal hunting is often associated with projectile weapons in the archaeological literature, there is no reason to assume that it was the only method employed by people at Star Carr. Although direct evidence for trapping technology is lacking at the site, ethnographic accounts of hunter-gatherers do describe the use of traps and snares in the hunting of animals such as elk, red deer and bear (e.g. Nelson 1983; Nelson 1986). This includes the use of deadfall traps, spring traps and snares set across trails that the animals are known to use. Nor should we assume that the methods, tactics and technologies employed in large-game mammal hunting stayed the same throughout the time Star Carr was occupied. The changes in environment within the Vale of Pickering, combined with the impact of human hunting and shifts within the ecology of the Vale, would have led to changes in the behaviours of the species being hunted. This would have meant that the knowledge, techniques and technology involved in tracking and hunting would have been adapted and developed throughout the occupation of the site.

As well as hunting the larger mammals in the surrounding landscape, people at Star Carr were also killing smaller animals, either with projectiles or by trapping and snaring, as well as hunting wild fowl and fishing. As with the larger animals, these forms of hunting would have varied in terms of the technology and strategies that were employed and the places around the lake where they were carried out, depending upon the behaviour and habitats of the prey species. These practices would have been different to those employed in large-mammal hunting, not only in terms of the forms of weapons that were used, but also the numbers of people involved, and the scales at which they were carried out.

Of the smaller mammals, the best represented are beaver, though pine marten, hare, wild cat, fox and badger are all also present in the assemblage, albeit in very small quantities. Some of these may have been killed using projectile weapons; others were probably caught by trapping or snaring. The age-at-death profiles and depositional context of the beaver from Star Carr suggest that hunting may have been managed over a prolonged

Figure 10.2 (page 249): A dead fish speared on a barbed point from experiments using the replica bow (Chapter 29) (Copyright Aimée Little, CC BY-NC 4.0). 
period of time. Whilst beaver lodges would have formed visible markers within the landscape and would have been relatively easy to break in order to smoke out entire families of beaver, this form of hunting is essentially unsustainable, as Lake Flixton would have been unlikely to have been able to support multiple lodges based on its size. There are also ethnographic accounts of beaver spearing, staking out known beaver runs and ambushing the animals with long-handled spears as they make their way to and from the lodge at dusk and dawn. However, given the value of an intact beaver hide for the production of waterproofed items of material culture, many traditional hunting societies prefer to employ traps. Boas (1905), for example, describes a form of deadfall trap, which is set in water to catch beaver. As the beaver encounters the trap it activates a trigger that causes a heavy log to fall, killing the animal. Again, these traps can be positioned along beaver runs to increase the chances of success. Similar versions of deadfall traps are used on land for trapping small mammals including pine marten, where the animal is lured beneath the trap by bait, which is attached to the trigger (e.g. Drucker 1951; Nelson 1986). Such traps are often set up against trees and surrounded with small structures made from branches, known as a cubby. Alternatively, snares set across trails could also be used to catch animals such as wild cat and fox.

From the presence of fish bones and fish processing polish on several pieces of flint it is also clear that people were catching perch, pike and possibly other species of fish from the lake (Robson et al. 2016). Given the lack of evidence for fishing equipment, such as hooks, nets or net weights from the site it is possible that these were caught using projectiles that were either thrown or fired from small bows (Figure 10.2; Chapter 29). Both perch and pike may have been fished close to the lake shore as the two species spawn in sheltered lake margins, whilst pike may also have been attracted by the waste material deposited by people at lake edge locations (Robson et al. 2016). Small bows may have also have been used for hunting wild fowl within or around the lake. Most of the birds represented in the faunal assemblage are waterfowl and so may have been hunted within the wetlands or at the edges of open water, though some, such as the red-breasted merganser, nest on dry ground and so may have been shot at nesting sites at the water's edge.

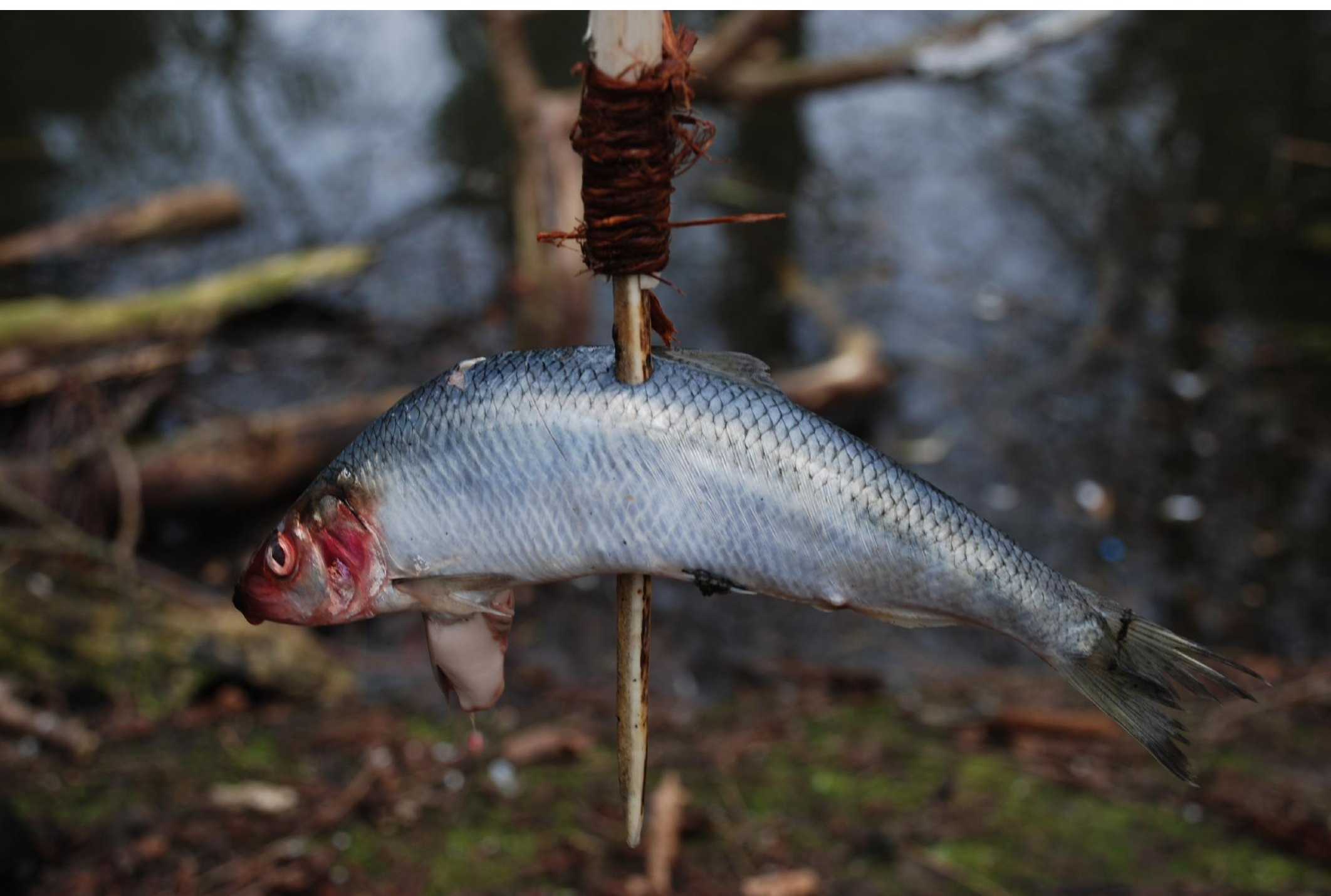


When discussing hunting in the past, it is easy to assume that animals themselves were somewhat passive within these encounters. We base our interpretations of hunting on faunal remains, themselves evidence for successful activities which resulted in the death of the animal. However, we should not assume that hunting at Star Carr had a 100\% success rate, and the actions of the animals themselves would have played a key role in this. Hunting large, seasonally aggressive animals, many of which were considerably taller, stronger and heavier than a human adult, would have posed some considerable physical danger to the hunters and so the actions of the animals within this encounter would have been brought into sharp focus. The healed lesions noted by Noe-Nygaard (1975) and Legge and Rowley-Conwy (1988) attest to unsuccessful hunting attempts following which animals escaped, whilst the presence of these bones within the Star Carr assemblage also demonstrates that individual animals were encountered more than once by hunters. These repeated encounters would have allowed for the recognition of individual animals and the development of relationships between individual people and animals over their respective lifetimes (Conneller 2011). What is more, the methods that were used to hunt animals drew upon understandings of the animals themselves, which recognised differences between species, and between individuals of different age and sex. This extended beyond an understanding of very general behaviours, such as habitats and feeding patterns, to specific aspects of an animal's character. Modern Koyukon hunters, for example, are aware of the inquisitive nature of lynx, and leave coloured ribbons or carvings of faces on trees by the traps they set for it (Nelson 1986). In this way, hunting articulates an understanding of animal behaviour and appreciation of animals as living, thoughtful entities with which people interact.

\section{Butchering and working animal remains}

These interactions continued after the act of killing, when people processed the bodies of animals for food and materials such as hides, meat, sinew, bones, feathers and antlers (Figure 10.3). When processing animal bodies, people at Star Carr made choices as to which particular materials they wanted to use and which would be discarded. 
Traces of these decisions are preserved in the fragmentation of the animal bone assemblage, the cut marks left on these bones during butchery, the wear traces on the flint tools used to carry out these actions and the working marks which have been preserved on the worked bone and antler, and the artefacts made from these materials.

In the case of the larger mammals, some initial butchery may have occurred at the place where the animal was killed. However, the evidence from the faunal assemblages indicates that much of the body was brought back to Star Carr. There, microwear on several flint tools and cut marks on a number of the bones show that the hides and meat were removed from the skeleton using flint to cut through the flesh and in some cases the tendons. If it had not already occurred, some of the animals were jointed, removing the limbs from body, and in some cases the bones of the limbs and the feet were also separated, though in others the bones remained articulated by their tendons.

Once the skin and flesh had been removed, some of the long bones were broken open to extract marrow by percussive action that removed one or both of the ends of the bones and split them longitudinally (Figure 10.4). In red deer, this appears to have been carried out most often on the metapodials, humeri, and tibiae, though other elements were also broken in a similar manner. In some cases the lower jaws of red deer and roe deer were also broken open to extract marrow through a series of strikes along the body of the mandible.

Particular parts of specific animals were also separated from the body to be used as materials in the making of objects. This can be seen most clearly in the utilisation of the antlers of red deer. These were brought to the site by both collecting material following the annual shed in spring and removing the antlers from animals killed whilst hunting. The collection of shed antler requires some consideration; once shed, antler is often gnawed by rodents and other deer if left on the forest floor, and the lack of gnawing on the Star Carr antler suggests that it was gathered swiftly after being shed (Legge and Rowley-Conwy 1988). Given the dispersed population densities of red deer males living in woodland during the spring, the rapid collection of shed antler implies that people were aware of the presence of deer at specific times of the year for purposes that were not always directly linked to hunting. 
Figure 10.5: The removal of antler tines with a flint blade (Copyright Aimée Little, CC BY-NC 4.0).

The red deer antler brought to the site was almost always worked in some way. This usually involved the removal of the tines (Figure 10.5) which could be used, unmodified, in a range of different tasks including splitting wood, knapping flint, working other osseous materials and the application of the groove-and-splinter technique. This latter method of working antler involves the scoring of parallel grooves along the length of the antler beam to define a rectangular piece of material. The grooves are then deepened to penetrate the hard outer compactor tissue to get through to the soft spongy material within. The intervening rectangle is then prised away through the insertion of wedges and the cutting of short transverse grooves at each end of the splinter. Once removed, this rectangle (or 'blank splinter') can be worked with flint and coarse stone tools to remove the adhering spongy tissue to create barbed projectile points (Chapter 25).

Figure 10.3 (page 250): A replica arrow with feather fletching and animal sinew bindings (Copyright Aimée Little, CC BY-NC 4.0).

Figure 10.4 (page 251): Spiral fractures on mammal bones are thought to have resulted from marrow extraction, as seen replicated here (Copyright Aimée Little, CC BY-NC 4.0).

Figure 10.6 (page 253): Splitting a metatarsal bone so that it can be worked into a bodkin (Copyright Aimée Little, CC BY-NC 4.0). 
In terms of the use of osseous materials (bone, antler and teeth) offered by animal carcasses, the occupants of Star Carr appear to have held a distinctive set of values which guided their decisions. Red deer antler was strongly preferred for making osseous material culture, with the vast majority of the red deer antler available being worked in some way to extract rectangular blank splinters. Whilst the extent to which individual pieces of antler were worked varies, the dominance of worked red deer antler over unworked antler indicates that making barbed points was a persistent concern for the people who spent time at Star Carr.

Other osseous materials were also worked at Star Carr, although not on the scale of that seen for red deer. The only identifiable animal tooth bead from the site was also from red deer: a perforated vestigial canine; the other tooth bead recorded only as 'cervid' (Clark 1954). Red deer canines were the tooth of preference for Upper Palaeolithic bead making in Western Europe (Taborin 2004; White 2007) but also had a wide currency in the Mesolithic. Small quantities of elk antler were also brought to the site in both shed and unshed forms and used to make elk antler mattocks, a heavy tool which when hafted could have been used to work wood. Aurochs bone was used to create heavy-duty chisel-like tools, whilst elk metapodials were occasionally used to create slender bodkins, which microwear analysis has shown may be involved in the working of plant materials and basketry (Figure 10.6).

An important and unusual form of osseous material culture which features at Star Carr is the worked red deer skulls. These were selected to include both male and female animals, young and old, with antlers in varying stages of development and shedding. These have all been worked to remove the facial bones, dentition and lower jaw. In many cases the back and base of the skull has also been trimmed away to leave the frontal and parietal bones, hence the term 'frontlets' which Clark used to define these artefacts. In a minority of cases, these remaining bones were then perforated with small holes ranging in number from one to four. When present, the antlers were worked extensively using the same groove-and-splinter process used to make blank splinters for barbed points. In some cases, this involved reducing the antlers to small stumps, in others an impression of 


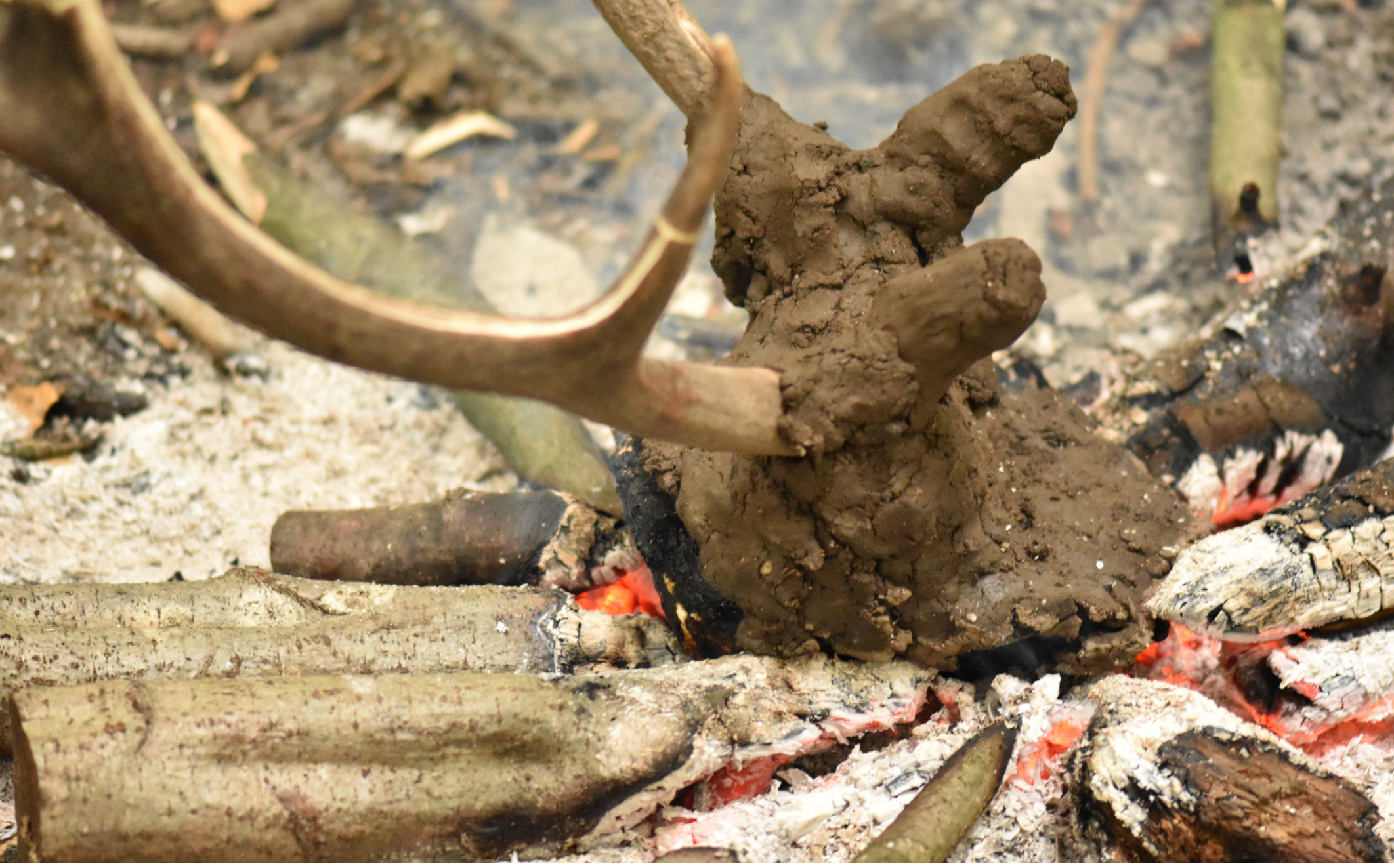

Figure 10.7: Red deer crania packed with damp clay and placed over hot embers (Copyright Aimée Little, CC BY-NC 4.0).

the antlers' original form is left whilst removing more than half of the circumference of the beams and tines. In these instances, the application of the groove-and-splinter process varies slightly to that used when working other antlers, with the spongy tissue within the beam being scooped and scraped away to leave hollowed-out antlers behind (Chapter 26).

Experimental work has established that much of this reduction of the skull would have involved covering the areas which were intended to be retained in wet clay, heating the fleshed head in a hearth for several hours, and then pecking away the unwanted areas of skull with a small hammerstone (Figure 10.7) (Little et al. 2016). This process also allows the brain to be cooked and extracted whilst opening the skull. In contrast to the working of the skull, the groove-and-splintering of the entire beam, to the extent seen in some of the frontlets, would have taken a considerably longer amount of time and effort.

Conventionally, these artefacts have been interpreted as 'headdresses', based on the perforations (which may have allowed webbing or strapping to be attached), the reduction of the antlers (which would have reduced the weight of the frontlets considerably) and what Clark described as the smoothing of the interior of the braincase (to make them a more comfortable fit for a human head). This concept of a headdress has stimulated discussions of their function; as disguises for hunting deer (Clark 1954), as costumes for ritualised dance (Clark 1954), or as tools of corporeal transformation to be used in the negotiation of interspecies relationships (Conneller 2004). However, recent experimental work has cast doubt on their suitability as headdresses, without the aid of considerable padding and attachment (Street and Wild 2015). Given the uncertainty over precisely how these objects were worn on the body, and the obvious need to refer to ethnographic literature in order to understand these enigmatic artefacts fully, we propose the use of the term 'mask' to describe them. The anthropological literature on the significance of making, using and depositing masks within hunter-gatherer groups is substantial, and the wide range of face, crown, pocket, finger and knee masks being documented amongst different groups leaves the issue of precisely how they were worn open to further debate. 
Uniserial barbed points, in a variety of sizes and forms appear to have been important to the inhabitants of Star Carr and are by far the most numerous type of bone or antler artefact recovered from the site. At other Mesolithic sites across Europe, large-mammal long bones (specifically metapodials) are carefully prepared and split to make similar rectangular blanks. However, the inhabitants of Star Carr seem to have been less concerned with using animal bones to make barbed points; the evidence for the careful splitting of mammalian long bones is far outweighed by the amount of animal bone which has been broken apart percussively for the extraction of marrow. The decision to do this renders the broken bone material useless for barbed point production, due to its irregular size and shape. Clearly, bone marrow was deemed a valuable resource in its own right and antler seen as a more suitable material for the production of barbed points.

These values appear to remain consistent throughout the site's history, with worked antler and barbed points being deposited in different areas of the wetland throughout the sequence. They mark the inhabitants of Star Carr apart from groups of people living in Northern Germany, Denmark and Sweden in the Early Mesolithic, who favoured the use of metapodials and split rib bones for making very similar types of barbed points (David 2005). The fact that these people shared common ideas concerning the shape and form of their hunting tools, yet had quite different attitudes to the materials from which they were made, is a fascinating insight into the relationships between different groups of people living around Northern Europe at this time. Whilst they may have agreed on the form that material culture should take, their understanding and values of animal bodies was distinctly different.

\section{The curation and deposition of animal remains}

Other sets of values structured the ways in which the remains of animals were treated after they had been butchered and worked to manufacture objects. This can be seen most clearly in the dense deposit of bone, antler, flint and wood that was recorded from the baulk between Clark's trenches and which had been deposited into the lake edge wetland. The faunal material had been generated through the butchery and subsequent processing of animal carcasses. This had been deposited with the skulls of red deer that had been worked to varying degrees, worked antler, a large number of artefacts made from osseous material (notably barbed points but also an elk metapodial bodkin and scrapers made from aurochs metapodials), wooden artefacts and woodworking debris, and worked flint. The radiocarbon dating shows that this material was deposited over a very short period, possibly even as a single event, though patterning in the densities of this material suggests either several acts of deposition or the actions of a number of people.

There are several aspects of the assemblage that suggest that the material had been deliberately brought together and deposited, rather than resulting from ad-hoc, casual disposal. To begin with, some types of artefact were disassembled prior to deposition. The barbed points, for example, would originally have been hafted (as is indicated in the microwear analysis), but the absence of spear or arrow shafts within the assemblage suggests that these had been detached and deposited elsewhere. What is more, this was carried out on both intact (or near-complete barbed points with only minor damage) and on broken barbed points where just the tang survived. The same is true of a dehafted flint projectile point and of the antler axes and mattocks, all of which lack evidence for a handle with the exception of a single possible example where the handle had been burnt (Clark 1954:158; though see Chapter 29), and include both broken and more intact examples.

There is also evidence for the curation of artefacts. In the case of the red deer masks, both 'finished' and 'unfinished' examples were deposited together in the assemblage. In the case of 'unfinished' masks, these have had the facial bones and lower jaw removed, but the lower areas of the skull had not been trimmed away. Experimental work has established that the reduction of the cranial bones would have involved placing fleshed skulls within hearths (Little et al. 2016), but as this area of the site was submerged during the period of deposition it is impossible for the assemblage of incomplete masks to be the product of simple abandonment during in situ manufacture. Instead, these objects have been brought together and deposited alongside 'finished' and possibly utilised masks. This can also be seen within the pattern of deposition of the barbed points. Both intact (and re-usable) barbed points were deposited alongside points which had been damaged in use (and would have been repairable) and points which were broken beyond repair. Furthermore, the broken tips and midsections must have been retrieved (presumably from the carcasses of animals) and retained in order for them to have been deposited along with the more intact examples and the broken tangs, which would have been 
brought to the site on the arrow or spear shaft they were initially attached to. Despite differences in their functional viability, all of these artefacts were curated and brought together for deposition during this particular phase of the site's occupation, seemingly based on what kind of object they were, rather than what state they were in. This may suggest a temporality to deposition; that certain things had to be brought to the Star Carr lake edge at a certain time, regardless of their usability or disrepair.

The evidence for curation is not limited to the deposition of these artefact types. The presence of clusters of animal bones and bone fragments with anatomical associations but which were not found in an articulated state suggests the retention of material from specific butchery tasks, such as disarticulation and dietary processing of lower limbs. Similarly the presence of a relatively large quantity of worked red deer antler and the diverse range of animal species within such a spatially and temporally limited assemblage would certainly suggest that material was being retained and then brought together for deposition.

Different ways of treating animal bodies are also evident at the site. Several centuries earlier, animal remains were being deposited into an area of the reedswamp at the edges of the detrital wood scatter. Unlike the faunal material in the area investigated by Clark, a large proportion of the assemblage was found in a semi-articulated state, and with large parts of the body still in their correct anatomical position (Chapter 7). This material either represents the deposition of one or more complete red deer carcasses that must have been dragged or carried into the lake edge wetland, or the bringing together of parts of the bodies of several red deer (including complete limbs and parts of the torso), which were then placed in the wetland in their (broadly) correct anatomical positions, perhaps to represent a complete animal. While this latter practice is thus far undocumented in the Mesolithic, the assembling of composite human bodies out of the remains of more than one individual is known from the British Neolithic (Fowler 2001) while an animal body was constructed from human remains in the Levantine PPNB site of Kfar HaHoresh (Horwitz and Goring-Morris 2004). Associated with this possible composite deer were red deer masks, barbed antler points and the unmodified skulls of a female red deer and a young elk, the latter associated with a phalanx which might suggest it had an attached hide.

There are clear differences between the earlier material deposited around the detrital wood scatter and the assemblage deposited later in the area investigated by Clark. Not only were some animals deposited as complete bodies (or body parts) without being butchered but all the red deer masks and barbed points were complete. However, there are also many similarities between the two areas of deposition: a focus on animal heads and masks, antler debris and a stone tool assemblage dominated by utilised blades. The similarities in the choices of materials and objects and the deliberate way they were deposited points to a broadly comparable tradition, in relation to particular ways of treating animals and objects made from their bodies. This tradition spanned several centuries with the later episodes of deposition referencing specific aspects of the earlier practices.

There is also evidence for the special treatment of the bodies of dogs. With the exception of the possible red deer carcass in the detrital wood scatter, the only near-complete animal carcass recovered from the site is that of a dog. While this may represent a natural death in the wetland, the possibility that it may be a purposeful deposition must be entertained. Furthermore, two dog skulls were recovered during Clark's excavations whilst relatively few postcranial remains were recovered in comparison (three femora and a tibia) (Clark 1954:71; Benecke 1987; Schulting and Richards 2009). The skulls are not over-represented in terms of the other elements and given that two femora seem to derive from the same individual (Schulting and Richards 2009, 499), partial dog carcasses may have been deposited in Clark's area. This is a pattern also seen at other sites around lake, notably at Seamer Carr where six articulated cervical vertebrae of a dog were recorded (Clutton-Brock and Noe-Nygaard 1990).

However, animal heads more generally do appear to have been singled out for special deposition at Star Carr and the presence of the two dog skulls does (albeit tentatively) also hint at special treatment for these remains. Dogs, as the only Mesolithic domesticated animal, may have had an ambiguous role in Mesolithic societies, living with humans, yet not actually human. There is ample evidence that in later Mesolithic contexts this ambiguity was played out in mortuary contexts, with some dogs receiving burial and grave goods analogous to high-status humans, while others were disarticulated or killed and thrown into human graves (Larsson 1990). The current evidence from Star Carr also hints at differential treatment of dog remains, most likely as a consequence of the special role that dogs played as companion animals amongst Mesolithic groups.

Not all animal remains were treated in these particular ways. Relatively large quantities of bone were recorded from the dryland part of the site and whilst the poorer levels of preservation made it harder to identify them, the same sorts of elements (with the exception of complete heads) and species (apart from dogs) were being 
deposited in this area as in the wetlands. This takes us back to the point made earlier that decisions regarding the treatment of animal remains, including the objects made from them, may have been bound up in other aspects of people's lives, such as particular events and specific places, as well as broader understandings of the world.

The one animal species that we know to have been present at Star Carr but for which we have no evidence for the way their bodies were treated in death are humans, the remains of which are entirely absent from the site and from any of the other known areas of Mesolithic activity around the lake. Whilst it is possible that burial sites are yet to be discovered, their absence from a landscape that has been so extensively studied would suggest that human bodies may have been treated in other ways. This may have included practices involving the disarticulation of human bodies through excarnation and dismemberment, which are well represented in the record from other parts of Britain and North-west Europe (see Conneller 2006 and Gray Jones 2011 for a review of the evidence). Equally, bodies may have been cremated, a practice known to have played an important role in Mesolithic mortuary ritual sometimes in conjunction with other forms of body treatment (Gray Jones 2017). As Gray Jones has argued, widespread use of cremation could explain the apparent lack of evidence for mortuary practices, especially if the remains were not subsequently buried or were not accompanied by diagnostic artefacts (Gray Jones 2017, 50). The lack of any human remains from the Star Carr region precludes any further discussion of the potential forms that mortuary practices may have taken. However, what we can say with confidence is that given the lack of human remains from the site, the bodies of people and animals were treated differently in terms of the context of deposition and that lives that were so closely entwined were kept separate after death.

\section{The treatment of stones}

Of the stones found on site, flint was by far the most important: the vast majority of tools recovered from site were made from flint and it was a vital resource for the transformation of other materials. However, a wide range of other stones were used: chert, shale, sandstone, siltstone, greywacke, quartz, quartzite, pyrite, haematite and amber (fossilised tree resin) all show evidence of human modification. In addition we have evidence for unmodified stones that were transported into the wetland. Though many of the stones used on site share a similar source, they differ in their properties, different technologies were selected for their modification and they were used and deposited in different ways.

\section{Sources}

The glacial till that blankets the present east coast was probably the origin of the majority of stones employed on site; all can currently be obtained from it. However, the means by which they were procured may have differed. Though a stony glacial till underlies the site, the easiest way to obtain stones in a vegetated landscape is from watercourses and the coast, for groups where the sea was in reach. The latter seems to have been the source of most of the flint employed: the clear brown, black or grey or red speckled till flint favoured by Mesolithic groups which in general appears to have entered the Vale of Pickering in the form of small to medium beach pebbles with a heavily battered cortex. Currently this material can only be obtained from beaches in any quantity south of Flamborough Head and while the coastline was very different in the Early Mesolithic, the nearest beaches to Star Carr may not have been the best source of this material.

The coast is likely also to be the source of the amber and possibly the shale, though the delicacy of the latter might suggest derivation from a lower amplitude fluvial environment. The coarse sandstones probably derive from the latter; though water worn, some are still relatively angular. The lake itself is also a possibility. Haematite is also found within the local till but tends to be extremely degraded, so a different source may be possible. In contrast to the coastal sources of till flint and other stones, opaque white or grey Wolds flint was obtained locally from the Yorkshire Wolds, located at the southern boundary of the Vale. In the absence of evidence for Mesolithic flint mines, the likely source was head deposits on the edge of the Wolds escarpment or solution hollows on the chalk plateau itself.

Sources are important. We know that throughout prehistory certain sources were favoured and that their location often played a large part in how they were perceived (Bradley and Edmonds 1993). The association of the majority of the stone from the site was water and this may have engendered metaphorical associations between the two. 


\section{Selection}

Of all the stone materials imported to the area, till flint was the most important with great quantities moved to the Vale of Pickering over the course of the centuries it was visited by Mesolithic groups. Small- to mediumsize pebbles were favoured. Large cobbles were also used but were split into smaller units. Though it was the preferred flint source, till flint was often of poor quality containing flaws and fracturing along fault lines when knapped. Despite being the favoured source for both Final Palaeolithic Federmesser groups visiting the Vale, and for Deepcar groups in Northern England (see Chapter 11), Wolds flint found little favour amongst Star Carr groups in the Vale, with ratios of till to Wolds flint across Early Mesolithic sites in the Vale at between 5:1 and 20:1. However, Wolds flint was more frequently favoured for making axes, with 50\% of the axes at Star Carr made from this material. This is likely to be due to both the large size and often tabular or semi-tabular form of Wolds flint nodules, which leant it to the form of axes much more readily than the small round nodules of till flint.

Other materials also show degrees of selection. In comparison with shale that can be collected today from the nearby coast, the material employed for the beads is rounder, smaller, finer and a paler colour. There appears to have been a deliberate selection of this more delicate material. The similarity of these beads to those from the Nab Head in south Wales (David 2007) suggests understandings of the sort of blanks suitable for bead manufacture were more broadly shared amongst groups making Star Carr-type assemblages, despite both geographical and temporal distance. Taborin (2004) has noted a preference for either squat or elongated bead forms in the Upper Palaeolithic, linking these with female and male symbols respectively. While these two forms cover most bases, such shapes can also be noted at Star Carr, with an elongated 'celtiform' shale pendant, discovered by Clark (1954, plate XX, H), as well as round/oval shale beads and the triangular decorated shale pendant (Chapter 33).

The other main material selected for bead manufacture was amber, with three beads recovered in Clark's excavations. Amber has a long history of use as beads, employed since the early Upper Palaeolithic (White 1995). As well as having colourful and lustrous properties (Figure 10.8), amber has properties which might mark it out as a powerful substance: it can contain small pieces of vegetation or insects, can float in salt water, and can carry an electrostatic charge.

Other minerals may also have been seen as powerful. Pyrite generates a spark and was used to make fire. There is evidence in later prehistory at least that this may have been equated with the life force itself (van Gijn et al. 2006). Haematite may also have been considered a powerful material bestowing a red colour to skin or clothing (Walker 2015). While used for many mundane activities it also has a strong association with the dead, almost universally used in Upper Palaeolithic and Mesolithic burials, including those at Aveline's Hole, Somerset, which is dated only a few centuries later than Star Carr (Schulting 2005).

\section{Movement of material}

While it has generally been assumed that the materials recovered from Star Carr were collected by its inhabitants (Clark 1972), exchange is a mechanism which should not be discounted. Exchange of amber, for example, is a possibility: it is rare on east coast beaches today and was an object of some interest to Mesolithic groups more broadly, seemingly widely exchanged between Baltic groups (Zvelebil 2006). Haematite, also although potentially local, seems rather different in consistency from that generally present in the glacial till and pigments seem to have been moved long distances in Southern France during the Upper Palaeolithic (Chalmin et al. 2007). Exchange is also a possibility we should at least consider for till flint. Some of the till material recovered from the Vale is extremely poor quality, particularly from some sites such as Seamer C (scatter K). The distance to the coast is difficult to determine (and distances changed over the course of time that Star Carr and surrounding sites were occupied) but it is likely to have been in the region of 10-20 km. In the absence of suitable rivers connecting Lake Flixton to the coast (due to a glacial moraine the local rivers flow to the west, not to the sea), transportation must have occurred on foot. Nodules were often imported without being tested. It seems strange that material, known to often be of poor quality, was not tested before being brought this distance and this might indicate the presence of intermediaries. 


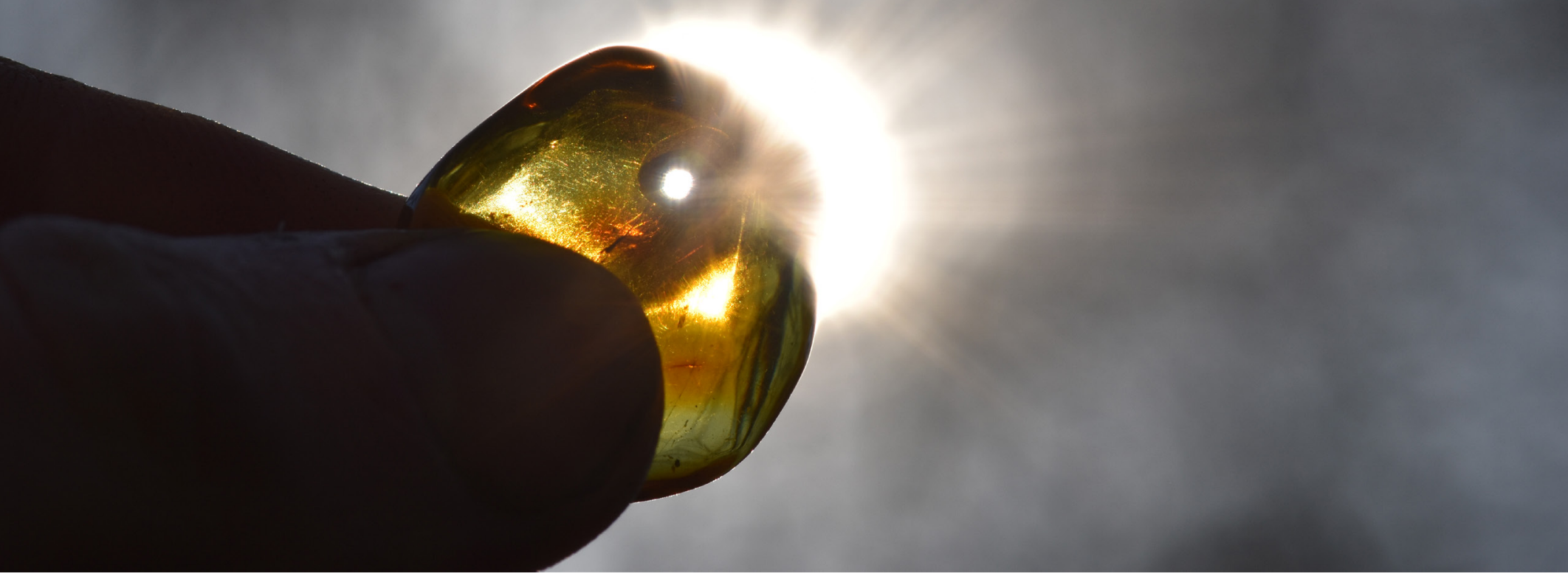

Figure 10.8: Replica amber bead with biconical perforation (Copyright Aimée Little, CC BY-NC 4.0).

Many stones are likely to have been brought to Star Carr unmodified; shale blanks for example seem to have been made into beads on site. Till flint was also often brought in as unmodified pebbles, though tested nodules with one or two removals are also in evidence. It seems likely that these were tested at source. Some raw material units were brought to Star Carr as preforms or partially reduced. Though some preshaping of cores may have taken place at source, an area dedicated to decortication of cores was located at Barry's Island within Lake Flixton, so it is likely that this occurred more locally. Large blades that were not produced on the site in which they were deposited are frequently recovered from Star Carr and other sites in the Vale; thus it is likely that people carried a stock of blades with them as well as flint in nodular/part reduced core form.

The preference for till flint led to the establishment of caches of raw material. Two such caches were recovered from Star Carr (Chapter 8). The largest of these was found in the eastern part of the site on the lake shoreline. It consisted of 19 pieces: large split nodule chunks, preforms and partly reduced cores. All are in a brown translucent flint which grades to opaque grey in its central part. Most of these probably derive from a single large split nodule; however, the removal of several blades from many of these pieces makes refitting tricky, although seven do refit. Three of these pieces have traces of use showing that they were used for cutting wood. This cache, when excavated, was associated with the roots of a tree. We cannot tell whether this was contemporary with the cache; however, the use of trees as markers for caches is known from the ethnographic record (Anderson 2006). The presence of woodworking traces on the cache might even suggest that the tree itself was marked, and such practices have been noted amongst the Khanty (Jordan 2003).

The second potential raw material cache consisted of only two pieces of raw material but both were large. These were found in between two planks of the western platform. The platform could possibly provide a marker for this cache, though the nodules were sufficiently heavy to have sunk into the lake muds beneath. An alternative interpretation is that this cache is related to the platform, either structurally or as a foundation deposit. 


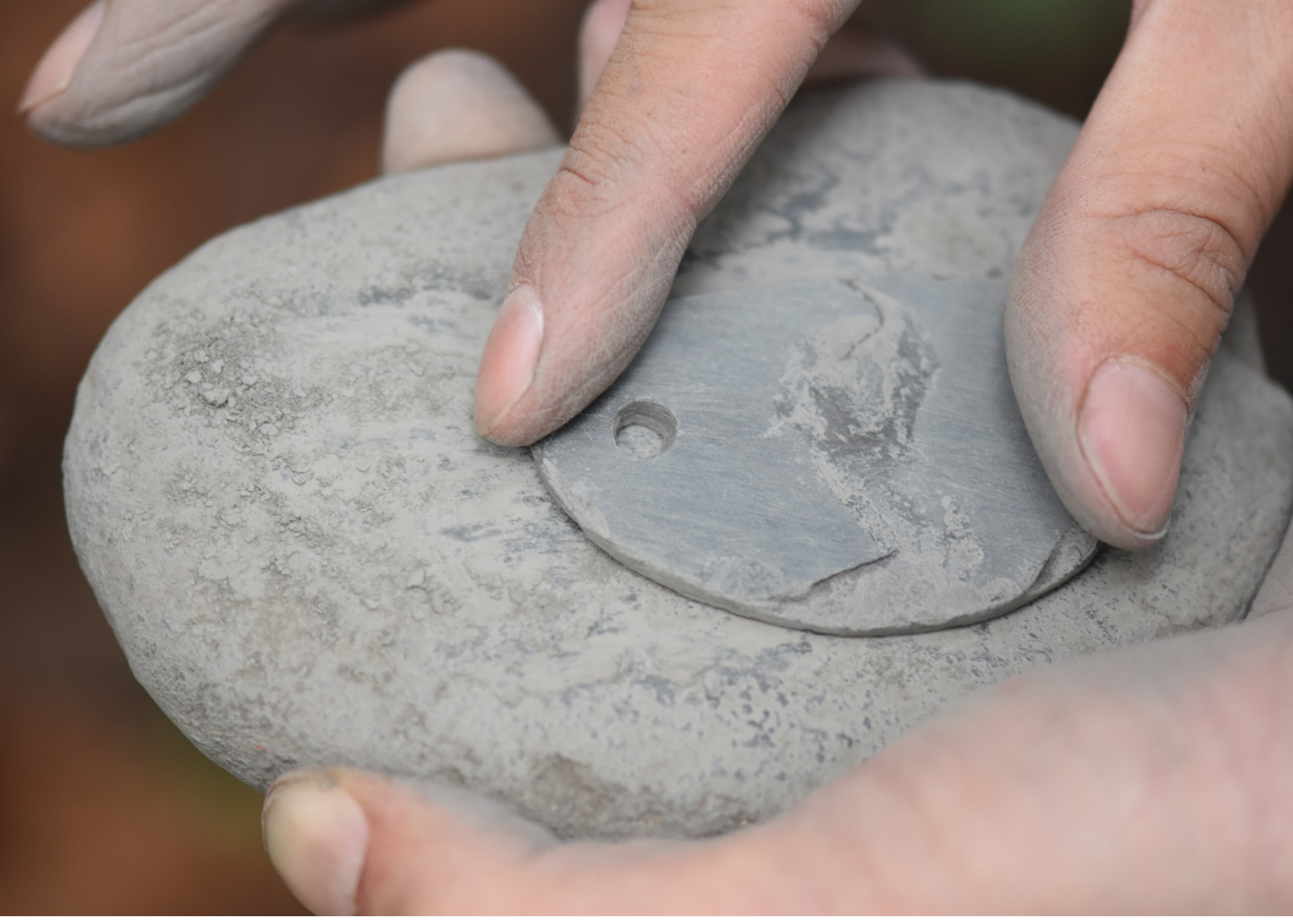

Figure 10.9: Grinding smooth a replica shale pendant using fine-grained sandstone (Copyright Aimée Little, CC BY-NC 4.0).

\section{Techniques and manufacturing}

A variety of techniques were used to work the stones found on site depending on the raw material employed. Flint and occasional till-derived cherts were the only stones flaked, sandstones tended to be pecked and shale was drilled and possibly polished (Figure 10.9). Flint nodules were prepared using natural ridges to initiate flaking. Smaller nodules tended to result in single platform cores. For larger raw material packages, cores were rotated and new platforms initiated to maximise the volume.

None of the stone technologies deployed at Star Carr were very complex or very time-consuming, whether these involved the manufacture of flint or coarse stone tools or shale or amber beads, and it is likely that these tasks could, in theory at least, be carried out by most members of the community. However, a variety of skill levels can be glimpsed in lithic assemblages from Star Carr and other sites around Lake Flixton, though variability in raw material quality may also be a contributing factor. Some refit sequences show high levels of skill and productivity, the best example coming not from Star Carr but from Seamer K on the northern shore of Lake Flixton (Chapter 11), where an elaborate multi-platform reduction sequence resulted in the production of 11 microliths from a single core. Conversely there is poor-quality knapping on display at Seamer C (near to Seamer $\mathrm{K}$ on the north shore), though here raw material is also extremely poor. There is also low productivity at VPD on the southern shore of the lake where a complete refitting sequence from decortication to the discarded core incorporated a single microlith. Similar features have been used to identify children or apprentices in the archaeological record, with children at the Magdalenian site of Etiolles given poor-quality raw material on which to practise (Pigeot 1990), a scenario that is also possible for Seamer C. 
The identification of specialists, that is individuals focused on a particular skillset, who produced things for the use of others and in return were supported by the community (Apel 2008), has been made in early prehistory (e.g. Pigeot 1990) but only in situations where the level of difficulty of the technology would be beyond most members of the society. In a situation, as at Star Carr, where it was at least theoretically possible for everyone to produce the tools used in daily life, albeit with varying levels of skills, identification of specialists is difficult. It is reasonable on the basis of the available evidence to suggest they were unlikely to exist but that some individuals were more skilled than others. At the late Magdalenian site of Etiolles where specialist knappers were present, the products of specialists were scattered across the site suggesting distribution of the specialist tools to other individuals. At Star Carr it may have been more usual for people to produce tools for their own personal use. A refitting sequence from nearby Seamer K, for example, contained a couple of tools which were left where they were made, probably manufactured by someone for immediate use. On other occasions, as with the intense microlith manufacture also at Seamer K, an element of provisioning for future use may be involved, with one or two individuals making things for the wider group.

The example from Seamer K shows people sometimes made things for immediate use and abandoned them. However, on occasions tools and blanks underwent greater levels of curation. Different levels of curation are evident for particular tool types. Scrapers seem to have been moved around sites less. Burins tend to have been moved from areas they were manufactured but were often abandoned adjacent to refitting burin spalls, suggesting discard in areas they were used. Microliths almost never refit and seem to have been highly mobile tools used in the broader landscape. Axes also seem to have extended life histories. While resharpening sequences have been refitted, axes have yet to be refitted to entire manufacturing sequences. In the axe workshop at Star Carr for example, the two axes that were manufactured were removed, whilst the examples that were just resharpened were deposited there. A large unfinished axe roughout recovered from Star Carr was $230 \mathrm{~mm}$ long. Other axes from the site range in length from 48 to $100 \mathrm{~mm}$, with an average of $67 \mathrm{~mm}$. If the unfinished axe is in any way representative of the size of material chosen for axe production this would suggest these objects were extensively curated, undergoing many episodes of resharpening over their lives. The axes at Star Carr were so small because they were important personal objects that were looked after for long periods of time.

There is also evidence that certain lithic artefacts were curated as personal toolkits. One such example is a small cluster or cache recovered from the end of the central platform. This consisted of 44 small pieces of flint, including heavily reduced cores, small bladelets and flakes. Almost all the pieces analysed had butchery traces, with the exception of one piece used to work wood. All pieces are small and the cores have reached the limit of their productivity. The impression is of a small toolkit belonging to someone involved in processing animal remains. Lithic artefacts recovered from the eastern dryland structure give an impression of household possessions: three axes were recovered from this structure of which one has a refitting resharpening sequence. A scraper had been used, then resharpened and not subsequently used. A large knife used for woodworking was found in the structure but had not been made there. A small core, near the end of its use life but not entirely exhausted and that had been used extensively to the west of the structure was also recovered from within the structure. The impression is that curated pieces (personal or household possessions) were brought into the structure and stored there, aggregated for use in the craft activities and the food preparation that took place there.

While the non-flint stones have a restricted set of functions, as ornaments (beads) or to make other tools (such as a shaft straightener), flint is remarkable for its sheer range of functions: as tools to make other tools, such as barbed points, digging sticks and bows; other items of material culture such as beads, clothing, antler frontlets, bags, baskets and mats; structures, such as houses and platforms. It was also vital for everyday activities such as killing and butchering animals, harvesting plants and food preparation. It could be used for cutting, sawing, chopping, piercing, hammering, splitting etc. It was the glue that held Mesolithic life together.

Though flint was ubiquitous in Mesolithic life, it has generally been viewed by archaeologists as a mundane, functional material, devoid of the significance of rare organic artefacts such as antler frontlets. This may partly have been the case, as things that are often the most ubiquitous are the most taken for granted. However some flint artefacts may have been curated possessions which acquired extended histories. Flint tools also played a role in the unusual depositionary practices focused on the wetland. These wetland flint assemblages, based on the deposition of tools and used pieces, are the product of careful selection, with only particular pieces (mainly large used blades and some formal tools) suitable for deposition. This is a very different set of material to that deposited in middens, or left on knapping stations, which can be characterised as burnt material, 
waste, including very small chips and exhausted tools and cores. There is no doubt that some flint debitage was abandoned where it fell during routine knapping activities, but for other pieces, particular rules came into play when it came to their deposition.

What these rules were is more difficult to understand. It may be that the nature of the acts undertaken with the tools found in the wetland made it appropriate that they were deposited with a range of animal remains and unusual organic material culture. There is evidence elsewhere in Europe for the special treatment of flint associated with important acts and rituals (Conneller 2011). The deposition of the small cache/toolkit associated with butchery (described above) could be interpreted in several different ways: an accidental loss of a bag containing a personal toolkit, or alternatively the deliberate deposition of lithic material associated with the butchery of an important animal. It bears similarities to other acts of animal deposition in that it seems to have been wrapped in a bag or skin, as may have occurred with the elk skull in the detrital wood scatter, or with the antler frontlets which may have had skin attached and thus may also have been wrapped. A further possibility, if indeed this is a personal toolkit, is that this may have been placed in the waters of the lake on the death of its owner, destruction of personal objects at death being a common feature in both archaeological cases and in ethnographic accounts (e.g. Little et al. 2016).

The beads recovered from the site also have ambiguous depositional contexts (Chapter 33). The engraved pendant was recovered from the lake and is the most obvious case of the special deposition of a bead (Milner et al. 2016). The other beads were probably found in wetland edge contexts. This is the case, at least, for the two examples recovered during the recent excavations and the majority of the beads found by Clark cluster around these two. Of note amongst this grouping are two tight clusters of 10 and 12 beads respectively which Clark $(1954,165)$ suggested represented lost necklaces. Beyond this main concentration are a perforated red deer canine and an amber bead which from their location plotted by Clark may well derive from within the large deposit of material in Clark's area, and three beads found in Clark's eastern trench which could derive from a reedswamp or fen context. Two of this latter grouping, an amber and a shale bead, lay in direct contact suggesting they had been strung together.

The main cluster of beads corresponds with the main concentration of awls at the site. Many of these have mineral traces suggesting these were used for the manufacture of beads in this area. If this is a manufacturing area, it seems strange that this is where beads were also recovered in large numbers; there is nothing to suggest they were manufacturing rejects. Caching is a possibility, particularly for the clusters; however, evidence from the two beads recovered during the current excavations suggests they may have been worn. Neither of these two beads is broken, which might have suggested this was an area of clothing repair where broken beads were discarded and new examples sewn back onto clothing (wear traces suggest that these Mesolithic beads were attached to clothing rather than strung as necklaces, as is usual amongst early prehistoric beads).

Two further possibilities might be entertained. It has been argued that barbed points were made at Star Carr, used in the wider landscape and then returned to Star Carr for deposition. The same could be true of beads. An alternative interpretation would the same sort of decommissioning that has been argued might be responsible for the butchery toolkit deposition. Beads and clothing with a close connection to the human body might be the obvious thing to decommission on someone's death. Beads are common finds in graves and though unlikely to mark graves here, would be a symbolic means of marking someone's death at a particular place, at a time when human bodies were probably disarticulated and bones curated by the living (Conneller 2006).

\section{The treatment of plants}

The diversity that we can see in the ways that people engaged with animals and worked with stone, can also be seen in their use of plants. Although plants and plant-based crafts are often underrepresented in our narrative for the Mesolithic (Little 2014; van Gijn and Little 2016), it is clear from the data recorded at Star Carr that plants formed an important part of the material repertoire of the lives of people who inhabited the site. They were utilised for a wide range of purposes, often involving particular forms of technology, skill and knowledge that varied depending upon the species being worked and the nature of the object that was being produced.

Of the tree species, willow and aspen were used extensively for the manufacture of artefacts and for the building of structures, although a range of other species were also utilised more occasionally such as alder, alder buckthorn, elder and species of birch. In some cases, particular species were chosen for specific tasks; for 
example, aspen preferentially chosen for platforms and willow often used to make dowels and digging sticks (Chapter 29). It is also clear that particular trees were chosen depending upon the task at hand. For the building of the timber platforms, for example, people selected straight-growing trees with few side branches; properties that would make the wood easier to work (Chapter 28). This meant preferentially avoiding using the trees growing at the water's edge and selecting from those growing in dense woodland (though not necessarily far from the site). In other cases they harvested coppice, either naturally occurring or deliberately managed, for roundwood stems that they utilised as tools or (possibly) building materials. The more occasional use of other species may reflect their sparsity within the local environment, or the ad-hoc nature in which plant materials were used. However, it is also possible that specific species were used for particular tasks, either in terms of the artefact that was being manufactured or the use to which it was put.

A range of technologies were utilised in the initial collection of wood. To harvest the coppiced roundwood, people used axes to cut the stem and where necessary tore the stem from its base, whilst larger trees may have been felled by ring barking, by rocking, with axes, or as natural tree falls. However, in some cases trees may not have been felled at all and timbers may have been split from living plants, a practice well documented ethnographically (e.g. Boas 1905). At Star Carr, this practice may be seen in one of the trees in the detrital wood scatter that had had its outer surface tangentially split away, and the large numbers of tangentially outer split timbers found at the site.

The ways in which wood was subsequently worked and the technology that was employed also varied depending upon the motivations of those who worked it, whether this was for hafting tools, making structures or extracting dyes or even medicines. The clearest evidence we have for the use of the large timbers are the wooden platforms that were made using whole trees, stripped of bark and any branches and timbers radially or tangentially split using wedges and hammers, and then (in at least some cases) trimmed and hewn with axes. However, the quantities of woodworking material incorporated into the platforms and the detrital wood scatter and the fact that the radiocarbon dating shows that some timbers were being reused, would suggest that split timbers were also used for other tasks at the site such as the structures on the dry ground.

In other cases, timber was half and quarter split and then reduced further to make artefacts such as the bow, or worked into dowels to produce objects such as digging sticks, handles for use with other artefacts, or (possibly) spears. The precision with which some of this material was worked suggests they were finished using fine flint tools (such as flakes or blades), a point that is borne out by the results of the microwear. Forms of woodworking other than splitting can also be seen. A wooden 'platter' had been carved from a larger piece of wood, one piece of roundwood had a small hole drilled or cut through it, and microwear on a hafted flint blade shows that it had been used to scrape and groove wood.

Other parts of trees were also utilised, involving different forms of technical skill and knowledge. A withy was made from twisted strands of willow, perhaps to bind two timbers together, whilst microwear on a flint blade shows it was used to separate the bark from bast, part of the process for manufacturing cordage. Birch bark was also cut from trees and used to make mats, rolled around sticks and used as torches, or heated in rolls to produce resin.

As well as working with wood and bark, people also harvested and utilised herbaceous plant species at Star Carr, tasks that focused largely (though not necessarily exclusively) on wetland vegetation growing at the water's edge. The microwear analysis shows that people used flint tools, some of which were hafted, to cut and scrape siliceous plants. In some cases these tools may have been used to collect reeds that were growing in shallow water close to the shore. In others, tools with siliceous plant polish (mostly unretouched blades) were probably used to scrape reeds, extracting fibres for cordage, basketry and so forth. These activities seem to have taken place mostly at the lake edge, suggesting the first stage in plant working took place in situ, perhaps with the later stages (after the fibres were extracted and there was no need for a flint tool), taking place on drier land. However, indirect evidence for plant working is not restricted to flint tools, as the presence of plant polish on the tip of the bone bodkin has confirmed. It is possible this object was used in basketry, or perhaps as a clothespin for bark-cloth. In addition, it has been suggested that the paddle-like wooden object excavated by Clark (1954), may have been used for beating/softening plant fibres (Chapter 29).

Despite a relatively rich body of evidence, it is likely that the full range of material made from plants at Star Carr was far greater than that recovered during the excavations. Cord, produced from the fibres of nettles or wood bast, would have been an important and widely used resource (Figure 10.10), as would mats made from weaving or stitching reeds, and baskets made from cord, bark, or woven reed or thin stems. However, if we 
Figure 10.10: Preparing nettle cordage (Copyright Aimée Little, CC BY-NC 4.0).

take our cue from the ethnographic data we should probably be thinking far more broadly, of objects as diverse as cradles, toys, mallets, log ladders (particularly if people were splitting timbers from living trees), boxes and boats. Plants may also have been used as dyes, glues or as medicines. In some cases, some plants may not even have been modified in order to have been used. Several pieces of roundwood found at the site had been utilised with little or no significant modification and the central hollow of the eastern structure is thought to have been floored with plants, perhaps reeds or ferns. In addition, the use of plants could have been used in smudge fires (to repel insects) and moss could have been used for babies' nappies (e.g. Nelson 1983).

While the evidence remains elusive, it is also likely that plants would have been collected and consumed as food. From data collected on other Mesolithic sites in Northern Europe this is likely to have included soft fruits, such as wild strawberry, the rhizomes of wetland plants such as bulrush, and the seeds of the water-lilies, all of which were present in this landscape. As with the use of plants in craft activities, the collection and subsequent processing of plant food might have involved the use of other tools: flint to cut material, wooden digging sticks to extract rhizomes, baskets to collect the materials, and in the case of water-lilies, boats to harvest plants from areas of deeper water.

The collection and working of plant materials at Star Carr was complex, diverse, and multifaceted. As with the working of stone, tasks involving the use of plants would have been undertaken at different scales and would have been carried out in response to an immediate need (such as the utilisation of unmodified roundwood as a digging stick) or in anticipation of future events (such as the preparation of timbers for the wooden platforms). The different tasks often involved different forms of technology and physical engagements with the plants themselves. They also drew upon knowledge and skills that were specific to the materials that were being worked and the objects they were being worked into. Knowledge of the physical properties of plants lay behind 
the choice to use a certain species or the selection of an individual tree, as well as an understanding of how the material would respond when split with wedges, or cut, drilled, or scraped with flint tools. Technical skill and knowledge was also required to effectively use the tools and handle and manipulate the different plant materials, tasks that also required the correct application of physical strength. It is also interesting to note that there is no evidence of fire being used to work, transform, reduce or harden wood (Chapter 28).

As with hunting, the requisite skills and knowledge involved in plant use would have been learned through active participation, so we can assume that, on at least some occasions, they were undertaken by groups of people of different ages related through kin or other social relationships. Some aspects of plant crafts would also have involved the cooperation of other people. The construction of the timber platforms would certainly have required the work of numerous people to pull trees from the woodland into the reedswamp at the edge of the lake and to undertake the splitting of some of the larger timbers. However, other tasks may also have been carried out as a group, such as the harvesting and processing of reeds at the lake shore.

It is often assumed that many of these tasks were undertaken by women and children, though as with hunting, this binary division of labour on the grounds of gender is based on a poor reading of the ethnographic data. There are numerous examples where both men and women collect plant foods and work plant materials, and where gender divisions are apparent it often relates to specific types or species of plants or the objects they are being worked into (e.g. McGuire and Hildebrandt 1994). What is more, these are often bound up in broader cultural rules regarding appropriate ways of conducting oneself in the world. These not only include rules on who should work with certain materials but also underpin decisions on what species should be used for particular tasks, the way they are used, and how it and any waste material was discarded. This can range from rules relating to the way bark is stripped from plants in winter, to prohibitions against burning wood chips and shavings (e.g. Nelson 1983). Often, these relate to the belief that plants possess spirits with the power to give or take away a person's luck in their future dealings with plants, or in some cases, to harm or even kill those who cause them offence (Nelson 1983). Though we lack the archaeological evidence for such beliefs, we should certainly consider that they may have structured the way people used and disposed of plant materials at Star Carr given the formalised manner in which the bodies of animals were dealt with.

\section{Assembling things, making space}

A popular image in archaeological reconstructions is a lone craftsperson, working flint or bone. However, few technologies are solo endeavours, depending instead on interactions between a range of different people and materials (Finlay 2003; Conneller 2011). It has been possible to reconstruct some of the interactions of different materials, and by inference, technologies and people, through microwear analysis. From this we can see that flint was clearly an important intermediary in the transformation of a wide range of materials, being used to work a broad spectrum of substances including antler, bone, hides (dry and fresh), wood and siliceous plants like reeds, as well as minerals, such as shale. Organic substances were also involved in such interactions, notably the use of elk bone to work plant matter, red deer antler, which may have been used as wedges for splitting wood and as hammers for flint working, or aurochs bone, which was probably used to scrape substances such as hide.

Furthermore most things made and used at Star Carr were, in one manner or other, composites, involving different materials and sets of technical knowledge. In some cases the composite nature of the object is obvious in the combination of different parts, such as hafts or shafts, binding agents and flint. Microwear evidence demonstrates many different artefacts made and used at Star Carr were hafted. These include blades, flakes, microliths, axes and scrapers; with hafts made of bone or antler or wood; mastics made from birch resin and hide bindings. Similarly, the dryland structures were made up of wooden poles, bound by cordage or withies and covered with woven mats, bark or hide. The production of these things thus brought together many different materials and technologies. What is more, if we follow Finlay (2003) and assume that at least some components were made by different people, the acts of making composite objects articulated social relationships between different people. Beyond this, making things articulated relationships between people and places, what Lesley McFadyen describes as mobile space (McFadyen 2006, see also Conneller and Schadla-Hall 2003; Conneller 2005). At Star Carr, these relationships formed within the site, as people fetched things made elsewhere, assembled them together, used them, and discarded them in different places. They also extended to other parts of 
the landscape, from the coast where flint was collected to the places within and around the lake where people hunted or fished or harvested plant materials.

The social and spatial relationships made through craft production can be seen through exploration of a single tool type: hafted flint microliths (Figure 10.11). Whilst the hafts themselves have not been found, the presence of hafts and hafting agents has been identified through microwear and other forms of scientific analysis (e.g. Aveling and Heron 1998). Where it could be identified, the hafts were made from hard materials such as wood, bone or antler, whilst the binding agent (where they were used) was birch resin. Therefore, the making of these tools required a range of separate tasks, each with its own attendant technologies, skills and knowledge and potentially undertaken by different people. Flint was carried from the coast, worked using locally procured hammerstones to produce a blade which was notched, snapped and shaped into the microlith. If the composite tool was to be used as an arrow (and many of the microliths at Star Carr were used as projectiles), then a thin stem, suitably straight and of the correct thickness, had to be selected, probably from woodland adjacent to the site, cut and trimmed to size with a flint axe and straightened using a sandstone shaft-straightener. To bind the microlith to the shaft, birch tar was used, probably cut from trees using flint flakes or blades, and then heated in a hearth to produce a tar that was applied to the flint. Finally, fletching would have been added, perhaps made from feathers, cut with flint and bound to the shaft with thin cordage made from animal sinew or plant fibre.

As well as creating relationships between places through the procurement of materials used in their production, microliths, as flexible and mobile tools (almost never recovered from where they were made) linked Star Carr with places in the broader landscape. They were used across the Vale and most likely the adjacent uplands to hunt animals but also used around Lake Flixton as knives for working plants. One microlith had two use lives: as a plant-working tool and a projectile, making contact with hide, bone, meat and plants, before being finally discarded in the western structure.

The making of things was also a social activity that involved the collaboration of different people, as well as the bringing together of different materials and the utilisation of different technologies. Taking the eastern structure as an example, people would have worked together to collect and trim the poles that formed the frame of the structure, or to harvest the reeds or bark, which they then worked to create coverings for the walls and roof. Some people may have dug out the central hollow, others would have held the poles in place whilst they were tied together and the roof and walls lashed onto the frame with cord or withies.

As a collaborative task, the building of the eastern structure would have been a social event, where people interacted with other members of the group. If some tasks were organised along social lines, such as gender, age or familial relationships, then the articulated relationships between these groups perhaps provided opportunities for people to meet and interact, whilst also highlighting distinctions and divisions amongst the inhabitants of the site.

The social nature of the structure and the relationships that were created and reaffirmed in its making continued during its use. From both the faunal and lithic assemblages recorded from within the structure there is evidence for a range of activities, the nature of which are not incompatible with the interpretation of the structure as a dwelling, where the inhabitants prepared food, worked materials and maintained tool kits. The faunal material was highly fragmented, suggesting the intensive processing of the bone, either for the extraction of marrow, the working of bone into objects, or both. Flint tools recovered from the structure seem focused on craft activity, mainly working dry hide, perhaps as part of clothing manufacture, or working plant material (possibly for mats and baskets). The structure also seems to be a place where personal or household tools were brought for repair and storage. Two flint axes and a scraper, manufactured in another place, were brought into the structure, resharpened and then left there without further use. Microliths were also brought in and left, possibly from composite tools that someone brought with them, either to repair, or to salvage the flint from a broken haft. Conversely, burins were manufactured in the structure and then taken away and used elsewhere.

Not all of the activities carried out in this part of the site were undertaken within the physically bounded (potentially private) space of the structure. Scatters of worked flint and highly fragmented animal bone were recorded around the eastern structure as well as within the area of the former western structure. Here, people knapped flint, in some cases working partially prepared nodules that had been brought to the site, and

Figure 10.11 (page 267): Replica flint microliths being hafted to an arrow shaft with birch tar (Copyright Aimée Little, CC BY-NC 4.0). 


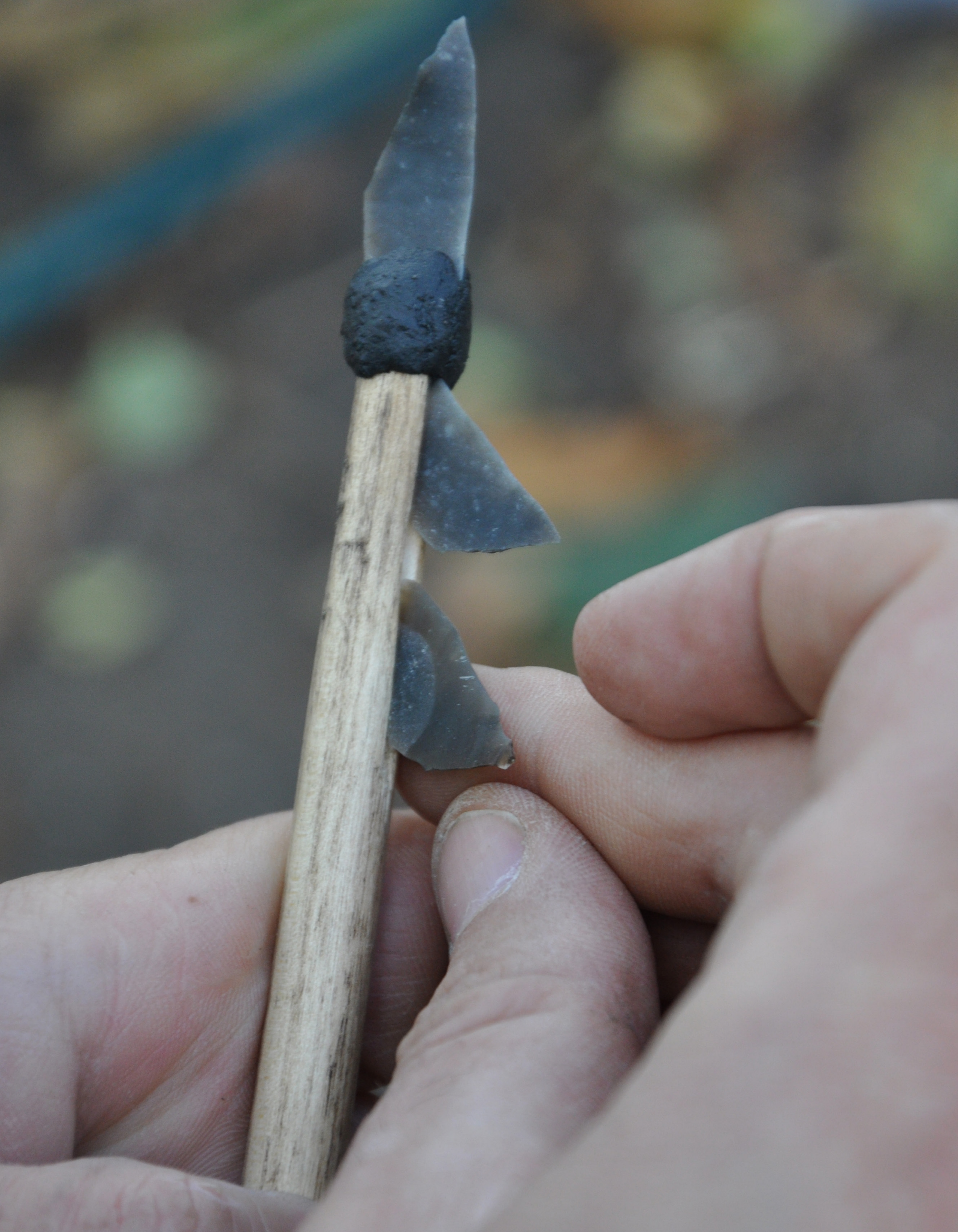


produced and repaired tools. These included burins (which were both manufactured and sharpened in this area), scrapers and microliths (the latter perhaps associated with the repair of composite tools), whilst an axe was sharpened and taken away. Flint tools were also used in this area; a burin to process fish, and a hafted flake to work bone, whilst the presence of flakes and blades with visible edge damage suggests other tasks involving the cutting and scraping of materials.

Some of these tools were also used to butcher and process the bodies of animals that were brought to the area around the structure, tasks that resulted in the deposition of animal bone as waste. Amongst this material, the presence of an articulating astragalus and calcaneus may reflect the discard of material from the dismemberment of an aurochs limb, whilst the concentration of fragmentary aurochs bone to the north-west of the structure has probably derived from the processing of a larger part of a carcass. Other faunal material in this area shows evidence for the breaking of bones, probably to extract fat or marrow, and longitudinal splitting, possibly as part of craft activities.

Some of the activities undertaken in this area were focused around hearths, the presence of which is reflected in the concentrations of burnt flint amongst the lithic scatters. The lack of more formal hearth structures, in the form of arrangements of stone or discrete pits with associated evidence for burning, suggest that these features were relatively shallow, or that fires were lit directly on the ground surface. From the analysis of charcoal samples from this and other parts of the site, they were fuelled with birch and willow/poplar (Chapter 32). The hearths themselves may have played a variety of roles; providing heat for the production of birch resin to use as a binding agent in the production of composite tools, smoke to repel insects and warmth for the people working around them. Some may also have been used in the manufacturing process of the red deer antler masks, others in the cooking of food.

Whilst some of the scatters of material around the structure appear to represent in situ activities probably broadly contemporary, they also include midden material derived from its clearance. Middening also appears to have made a significant contribution to the western part of the site. While there is likely to be some in situ material present possibly related to an initial use of the area as a structure (the western structure), the vast majority of the material lacks spatial patterning, and seems to have accumulated through the deposition of material gathered from elsewhere across the site, suggesting this area was used as a midden at some point in its history. This area has the greatest density of flint on site suggesting intensive deposition of material here. A large proportion of this material is burnt, suggesting it often represents debris related to the clearing out of hearths and possibly the clearing out of structures more generally. Flint densities are high in the north-west part of the site and the edge of the scatter (Moore's area, see Chapter 8) next to the midden is suspiciously circular; it is likely that there were more structures within the vicinity of the midden, beyond the northern edge of our trench (an area unfortunately truncated by both a field drain and the Hertford Cut).

The burnt material from the midden includes both flint and animal bone and is heavily fragmented in comparison with other areas, suggesting material that was cleared from areas with a lot of use. Within this midden were high proportions of utilised flint flakes and blades, along with more formal tools. Microwear shows that these were being used for a range of different activities including butchery and craft activities: the working of siliceous plants, bone, drilling stone and hide working. Several projectile points were also recorded, one of which had been reworked into a tool for plant use. Amongst this material was highly processed animal bone, probably waste from butchery and craft activities, including bone and antler working and clothing production.

The Star Carr midden (Chapter 35) is just one of a series of middens identified in Early Mesolithic contexts, such as Faraday Road (Ellis et al. 2003) and Three Ways Wharf (Lewis and Rackham 2011), which have been overshadowed by the rather more obvious later Mesolithic shell middens of Oronsay on the west coast of Scotland. Given arguments surrounding the significance of these later Mesolithic midden deposits (Pollard 1994; Pollard 2000) and of middens in later prehistory (Garrow et al. 2005; Jones 1998; Pollard 2001), a consideration of the broader social and symbolic significance of the Star Carr midden seems in order. The midden at Star Carr shared many features with other prehistoric middens with high levels of burning and fragmentation, possibly an effort to homogenise the midden into a singularised entity (Jones 1998, 310). Middens are memorialisations of past actions: visual and often olfactory evidence of the actions of past people and the bringing together of materials bearing traces of actions that occurred in particular parts of the landscape. Burnt material appears to have been of interest to Mesolithic people, being found in Mesolithic pits across the country (Blinkhorn 2012), suggesting that on certain occasions it may have been important to dispose of hearth debris in special ways. Burning transforms materials: making flint and bone appear similar, fragmented, opaque 
white, as occurred on this midden. There are also some suggestions that important objects were deposited here. For example, two burnt wildcat phalanges were found and Overton has pointed out the unusual representation patterns found for Mesolithic carnivores, with usually only isolated elements found on Mesolithic sites (Chapter 11; Overton 2016).

In the Early Neolithic, midden material appears to have embodied the activities of the group: when people left a place, they gathered midden material and buried this in pits (Garrow et al. 2005). Given that a lot of the material in the Star Carr midden derives from hearths, possibly from the structures, it is likely too that this material was redolent of group or household activities; its deposition perhaps symbolising the end of a period of occupation, or the start of a new episode of activity.

Like the structures on the dryland and the tasks resulting in the deposition of material in the midden, the building of the timber platforms employed different forms of technology and knowledge and the collaboration of different people. Specific trees were selected on the basis of their physical properties from particular places in the woodland. Bark was removed, and any side branches cut away. In some cases the trunk was split, probably by hammering wedges into it, and the timbers were trimmed and hewn with axes. In others, the whole tree was dragged or carried into the boggy ground of the swamp. However, in contrast to the areas of dryland, the platforms were clearly not places where people disposed of broken objects or waste materials. Nor were they places where tasks resulting in the deposition of large quantities of waste were carried out. Though some material is associated spatially with the areas around the platform, there is no indication of intensive episodes of flint or bone working. Instead, the material suggests more discrete episodes of deposition, possibly resulting in people keeping the platforms clear of detritus. The exceptions are several instances of more deliberate deposition associated with the western and central platform. In the case of the western platform, two large flint nodules and the mandible of a wild boar were present between the timbers. These are the only objects of their kind in this area and from their position they may have been intentionally deposited ahead of the construction of the platform.

The construction of the platforms was a significant undertaking and the scale of this enterprise can be illustrated by considering the amount of material that went into building the central platform. The 11 metres of the central platform that were excavated were composed of 26 largely unmodified tree trunks and 57 pieces of split timber, some over $5 \mathrm{~m}$ long, along with hundreds of smaller pieces of wood. As well as the effort involved in locating and bringing those trees to the lake edge and splitting the timbers, there was the manufacture of the necessary tools (including a lot of axes), many of which would have to be re-sharpened and repaired as the platform was being built. The logistics required to manufacture the central platform suggests it was a project that was planned and anticipated and its scale suggests that a large number of people came together to realise it. Tools may also have been made in anticipation and different people may have been involved in particular tasks. At some points groups of people would have worked together, lifting and carrying trees or dragging them across the ground and then positioning them into their correct place, whilst at others, people worked in smaller groups, splitting and hewing timbers. Some of these people would have learnt how to work the wood, where to drive the wedges into the trunk and control the split, following the examples set by those more experienced. Other people may have prepared food, brought water, or helped to repair equipment. As they finished, people would have waded, muddy, wet and tired from the lake edge swamp, their efforts perhaps marked by celebration.

\section{Understanding the world}

If the building of the central platform brought together large numbers of people, it was probably exceeded both in scale and intensity by the actions represented by the deposition of animal bone, flint and artefacts in the area first excavated by Clark. Based purely on the assemblage of material recorded from the baulk between Clark's cutting I and II, 560 specimens of animal bone were deposited here, along with objects made from the bodies of animals, and antlers that had been modified through this manufacturing process. The consistency of the radiocarbon dates suggests that not only was this material deposited over a short period of time but that all the material was contemporary with its deposition. In other words, the assemblage not only represents a discrete episode of deposition but contemporary episodes of hunting, killing and butchering animals, as well as the working of parts of their bodies into objects, and the tasks represented by the flint assemblage.

An obvious interpretation of large quantities of faunal remains deposited in a relatively short period is feasting. Meaty parts such as ribs and long bones are common in this assemblage, while mandibles and lower limb 
bones have been smashed for the rich marrow. Elk and aurochs were extremely large animals and Early Holocene red deer were also much larger than today. As such, the killing of several of these animals would amply provision a large gathering, an aggregation where several groups might meet up in the context of seasonal feasting and possibly also communal construction activity.

However, this is not the only story of this area: the assemblage is not simply the product of casual discard of feasting material, as there appears to be both structure to the deposit and a much broader range of material than can be neatly subsumed under the category of feasting. This latter includes lithic artefacts, particularly blades used in plant working, antler raw material and manufacturing waste, and a broad range of organic material culture such as barbed points and animal crania, including the red deer masks. There are unusual animal remains here also: the wings of two different birds, a crane and a black- or red-throated diver, part of a pine marten, the right forelimb of a wild cat and the only wolf remains from the site (a metatarsal, possibly indicative of the presence of a wolf skin). As has been argued for other depositionary acts at Star Carr, it may be that objects associated with important acts were deposited into the wetland: material from feasting, tools employed in key events, and the paraphernalia of ritual practices.

What people chose to deposit was guided by their broader understanding of the world and their interactions not just with other people but with the other beings that populated it, both animals and spirits. Anthropologists (e.g. Fausto 2007) have suggested that people who live by hunting and gathering are almost universally animist in their outlook and the evidence suggests the same was true for the people who inhabited Star Carr. Their world was one where animals could be seen to have the same desires and motivations as people and even to possess a soul; as a result, for people who depended on killing and eating these animals, the nature of human-animal interactions was one of great concern. Amongst Northern Eurasian huntergatherer groups, relationships between people and animals tend to be couched through concepts of reciprocity, where animals will choose to give themselves up to the hunter in exchange for respectful treatment of their remains. Jordan (2003) has described how amongst the Evenk, as amongst many hunter-gatherer groups, animal remains have to be treated with respect; as a result bear bones are deposited in deep pools and elk bones are returned to the forest. Jordan has urged archaeologists to seek similar patterns of deposition on archaeological sites.

Such motivations are likely to have guided the deposition of material at Star Carr. We note repeated patterns in wetland deposition from the earliest occupation of the site at around $9300 \mathrm{cal} \mathrm{BC}$ to the evidence contained in Clark's baulk, dated to around $8800 \mathrm{cal} \mathrm{BC}$. These include the deposition of faunal remains, barbed points, antler raw material, utilised flint blades, with evidence for a focus on animal heads, including the antler masks. There is some evidence that this practice, as at contemporary sites in Southern Scandinavia, was initially focused on the deposition of elk remains, perhaps in a bundle wrapped within their hide (Chapter 12); however, by the middle of the 92nd century cal BC at Star Carr, red deer began to be the predominant focus for the deposition of cranial material. The focus on red deer heads appears to have encompassed the treatment of antler too. While antler has been found on the dryland, quantities involved are relatively low and limited to raw material (though preservational issues need to be considered too); the preference for the deposition of both antler-working waste and barbed points seems to have been the wetland. Barbed points seem to have been aggregated from the wider landscape and returned to Star Carr for deposition. The only identified tooth bead also comes from red deer. It may be that the head of the animal embodied the soul or essence of the animal and it was this element that was particularly the focus of deposition (Conneller 2004).

The gatherings of people involved in feasting and other communal activities would have provided an opportunity for quite different and powerful social statements to be made. It is within this context that we need to consider the antler frontlets, or masks, recovered from Clark's baulk and other areas of patterned wetland deposition such as the detrital wood scatter. Masks allow the wearer to modify or transform their identity and change the way in which they are perceived by others around them. It is therefore interesting to consider the material choices made in the creation of these masks and the implications these may have for the identities which were being constructed. Red deer is a constant theme but the sorts of animals involved are diverse. One frontlet, for instance, comes from a large, powerful male red deer, whose remodelled skull surface indicates that he had been involved in many rutting fights before he died (Chapter 26). He was killed in the spring, shortly after having shed his antlers. However, two other frontlets appear to have been smaller, younger male red deer who were killed when their antlers were still attached to their skull. Another frontlet was made from the skull of a large female deer. These frontlets/masks therefore embody a variety of differing personal and seasonal 
information about these animals, the kind that would have been immediately obvious to people who spent large amounts of time stalking, killing and butchering red deer. This variety of animal biographies, at odds with a hunting strategy focused on the predation of younger animals, suggests that the original identity of the animal was important to those who made and wore the masks and that elements of these animals' identities were being chosen to be assumed by the mask wearer.

However, the identities created through wearing the masks may have been much more complex than a simple transference of the identity of the animal chosen for mask production. This is suggested through the working of the antlers, which often dramatically alters the form of the artefact and obscures the original age and sex of the individual animal. This can be seen in the significant reduction of the antlers of several frontlets, which leave either short spikes of antler or stumps at the burrs, thus creating the impression of a much younger animal, a female deer, or one whose antlers have just begun to regrow following shedding. The masks with more intact antlers have also had their form modified with the removal of the crowns and beams again creating the form of an animal younger than the individuals themselves (Conneller 2011). Further to this, we may also need to consider the masks as being composite objects, with other materials attached to change the form and meaning of the finished mask. This is implied through Clark's suggestion of the use of webbing or strapping but also supported by our experimental work which highlights the need for substantial support if these artefacts were to be worn and ethnographies of masks which often feature the attachment of feather, hide, cordage, carved wood and pigment. All of these materials bring their own properties and effects to the finished mask and have the potential to shape the identity of both the wearer and the mask itself.

Within a social context, masks have the power to transform the identity of the wearer, at the moment of adornment and removal. The reasons for wanting to shift identity are plentiful and Conneller (2004) has argued previously for a perspectivist interpretation of these artefacts which would have allowed the wearer to negotiate with non-human social beings (such as animals) to ensure positive relationships between people and the world around them.

These moments of transformation are powerful statements, distinguishing the mask wearer from non-mask wearers in their ability to shift identity. As such, it may be crucial to consider the social setting at Star Carr when interpreting these masks. This is equally important given that these artefacts have not been excavated from other sites around Lake Flixton. What is it about this particular site which makes it appropriate for the use and deposition of these masks? One key factor may be the size of audience for the moments of transformation. As discussed above, Star Carr appears to have been a place where large groups of people congregated. As such, it allowed mask wearers to demonstrate their ability to shift identity before larger numbers of people than would normally be in one place at one time. The audience themselves may have had a vested interest in the results of these shifts in identities; the negotiation of human-other being relationships may have consequences for entire communities and witnessing these events may have been seen as significant in itself. As such, the putting on and taking off of masks may have been an important social event for the Mesolithic inhabitants and formed one of the motivations behind unusually large groups of people coming together at Star Carr.

The temporality of mask wearing is also worth some consideration here. There are no obvious areas of wear on the excavated artefacts which would allow for a more detailed understanding of their use-lives. Some of Clark's finds featured broken perforations, suggesting a certain degree of heavier use prior to deposition, although this pattern is difficult to verify within the larger assemblage. This is due in part to the absence of microwear opportunities, in part to the mixed levels of preservation observed across the site, and in part to the realisation that perforations are not a definitive feature in the form of these artefacts. As such, whilst it remains possible that some masks may have enjoyed extended use lives and multiple wearers, there is little evidence on which to take this discussion further.

However, there may be other factors which affect the context of mask wearing which mark Star Carr out as different from other sites around the Vale of Pickering. The timber platforms and detrital wood scatter create a unique type of lake edge space which may have been an important part of the setting for mask wearing. They would have provided a cleared area upon which many more people could view the wearers and the communal labour invested in their construction may have imbued them, and the spaces they create, with a degree of social status. Conversely, the dryland structures would have afforded spaces for mask wearing where visibility was restricted to that of a privileged few. The presence of such a high density of intentionally deposited animal remains within Clark's area of the site may also have been another key factor. If the identities being created contained an element of animal affects, being in close proximity to such a volume of specially treated animal 
materials may also have been an important part of the context of mask wearing. Certainly, the deposition of the majority of the masks within this area of the site would suggest that they were linked in some way.

\section{Conclusions}

Clark's interpretation of Star Carr described the site as a base camp occupied by a small group of families during the winter months of the year, and probably revisited on a number of occasions (Clark 1954). Reinterpretations of the site in the 1970s and 1980s (e.g. Jacobi 1978; Price 1982) and the re-excavations in 1985 (Cloutman and Smith 1988; Mellars and Dark 1998) hinted at greater complexity. However, many commentators continued to follow Clark in assuming a single, simple interpretation of the site, taking issue with his interpretation only in so far as the season of occupation or the function of the site (e.g. Andresen et al. 1981; Legge and Rowley-Conwy 1988). We hope that this chapter demonstrates that such ideas can no longer be entertained. These excavations have revealed the complexity, scale and intensity of activity at the site: spanning around 800 years, the product of a variety of domestic, task-specific and ritual actions and capturing within the patterning of the remains the very different ways that Mesolithic people had of understanding their world. The site embodies the material remains of many different lives, separated in some cases by long periods of time. However, we should not assume that later inhabitants of the site held no memory of the initial actions of the pioneer groups who first made their camp on the edge of the lake as the similarities in patterns of deposition certainly hint at commonly held beliefs passed down by oral tradition. Other things changed, the focus and intensity of occupation may have waxed, and waned, but people continued to return to Star Carr, a place where countless generations had been before. 